\title{
A clínica dos casos difíceis no imaginário de estudantes de psicologia
}

\section{The clinical practice with difficult patients in the collective imaginary of psychology students}

\author{
Heloisa Aguetoni Cambuí1; Diana Pancini de Sá Antunes Ribeiro²
}

\begin{abstract}
Resumo
As condutas que ocorrem no contexto da intersubjetividade são organizadas a partir de campos psicológicos não conscientes, que influenciam as práticas individuais e coletivas. Torna-se importante, portanto, considerar o imaginário coletivo dos psicólogos em formação, na medida em que este pode interferir no exercício de sua prática clínica. Este estudo teve como objetivo investigar o imaginário coletivo de terapeutas em formação sobre o atendimento de pacientes considerados difíceis no setting analítico. Com base no método psicanalítico, esta investigação utilizou o Procedimento de DesenhosEstórias com Tema em entrevista grupal, com a finalidade de problematizar sobre as vicissitudes da clínica contemporânea com estes pacientes. Participaram deste estudo, oito graduandos do oitavo semestre de um curso de psicologia. O material resultante da entrevista constituído pelos desenhosestórias e a narrativa foi psicanaliticamente analisado, à luz da Teoria dos Campos proposta por Herrmann e em interlocução com o pensamento winnicottiano, permitindo a apreensão dos seguintes campos de sentido afetivo-emocional: "Insegurança", "Terapeuta Perfeito", "Mutualidade", "Vivência", "Negação da Loucura" e "A Loucura como Tal". De modo geral, as manifestações imaginárias dos estudantes de psicologia configuram a relação analítica com os pacientes difíceis, por meio da mobilização de sensações de insegurança, angústia, ansiedade, incapacidade e impotência.
\end{abstract}

Palavras-chaves: Psicanálise. Winnicott. Pacientes difíceis. Procedimento de desenhos-estórias com tema. Imaginário coletivo.

\section{Summary}

The conducts that occur in the context of intersubjectivity are arranged from unconscious psychological fields which influence individual and collective practices. Therefore, it becomes important to consider the collective imagination of psychology students as this may interfere about the exercise of their clinical practice. The aim of this study was to investigate the collective imaginary of psychology students about the clinical practice with patients considered difficult in the analytic setting. Based on the psychoanalytic method, this research utilized the Procedure of Drawings-Stories with Theme in group interview, for the purpose of discuss on the vicissitudes of contemporary clinical work with these patients. In the present study, participated eight undergraduates of the eighth semester of a psychology course.The resulting material of the interview constituted by drawings-stories and the narrative was

\footnotetext{
${ }^{1}$ Psicóloga. Mestre em Psicologia pela Universidade Estadual Paulista - Júlio de Mesquita Filho, Faculdade de Ciências de Bauru. E-mail: heloisacambui@yahoo.com.br

${ }^{2}$ Doutora em Psicologia. Professora Assistente do Departamento de Psicologia Clínica da Universidade Estadual Paulista - Júlio de Mesquita Filho, Faculdade de Ciências e Letras de Assis. E-mail: diana@assis.unesp.br
} 
psychoanalytically analyzed, in the light of the Multiple Fields Theory proposed by Herrmann and in dialogue with the winnicottian thought, allowing to apprehend the follows fields of affective-emotional meaning: "Insecurity", "Perfect Therapist", "Mutuality", "Experience", "Negation of Madness" and "Madness as tal". In general the imaginary manifestations of psychology students constitute the analytic relationship with the difficult patients by mobilizing feelings of insecurity, distress, anxiety, incapacity and helplessness.

Keywords: Psychoanalysis. Winnicott. Difficult patients. Procedure of drawings-stories with theme. Collective imaginary.

\section{Introdução}

A clínica psicológica contemporânea tem se deparado com a alta incidência de pacientes considerados difíceis no setting analítico (AIELLOVAISBERG, 2007; ZAMBELLI et al., 2013). Exteriorizam-se, nesses casos, dimensões intensas de sofrimento, que interrogam os limites teóricos e demandam a criação de manejos clínicos diferenciados embasados em pressupostos éticos.

De acordo com Forlenza Neto (2004), compreendem-se, por pacientes considerados difíceis, aqueles diagnosticados como psicóticos, esquizoides e borderlines, devido, entre outras razões, às dificuldades encontradas pelo analista ao realizar o manejo psicoterapêutico. No âmbito clínico dos casos considerados difíceis, Ferenczi (1992) destaca-se como precursor importante que, perante as limitações técnicas da época, introduziu questionamentos clínicos e propôs inovações a partir da ampliação dos recursos terapêuticos utilizados na análise desses pacientes. Luz (2010) afirma que as modificações inauguradas por Ferenczi no método psicanalítico, nos primórdios da psicanálise, ainda, se mantêm atuais na clínica com os pacientes difíceis.

Para Silva e Yazigi (2004), esses quadros clínicos são considerados representativos da atualidade e caracterizam-se por sujeitos cuja organização da personalidade excede os limites psicopatológicos entre a psicose e a neurose, de modo que, em alguns momentos, "funcionam como neuróticos, ora como impulsivos e profundamente intolerantes, ora revelam perda de limite de seu próprio eu, como os psicóticos" e, por vezes, "mergulham [...] em estados autistas ou refúgios subterrâneos de difícil acesso ao clínico" (SILVA; YAZIGI, 2004, p. 622). De acordo com Maia (2003), a clínica com os pacientes difíceis não se refere a uma nova modalidade psicopatológica. Contudo, enfatiza o aumento alarmante desses casos na contemporaneidade e a ampliação do movimento teórico-clínico psicanalítico, em busca de compreender e oferecer um suporte psicoterapêutico a essa modalidade de sofrimento.

Por sua vez, Figueiredo (2000) afirma que os processos contemporâneos de subjetivação são constituídos a partir da presença de um núcleo esquizoide e concebe, como exemplo clínico, os quadros borderlines, na medida em que estes apresentam alternâncias extremas entre a problemática narcisista e as angústias e as defesas características dos quadros esquizóides. Esclarecese que, semelhante aos pacientes psicóticos e esquizóides, os borderlines ou estados-limites, também, apresentam graves falhas na constituição psíquica que, por sua vez, concorrem para a precariedade do processo simbólico e para a fragilidade narcísica e identitária. Ressalta-se, entretanto, que a capacidade de teste de realidade, nestes casos, apresenta-se mais preservada, não ocorrendo o mesmo com os outros pacientes citados (FORLENZA NETO, 2004; PINTO, 2006). 


\section{Situações Limítrofes no Setting Analítico com Pacientes Difíceis}

Green (1990) diferencia os casos denominados neuróticos dos casos difíceis, a partir das dificuldades encontradas no manejo clínico destes. Segundo o autor, a análise dos casos "difíceis" exige a implicação ativa do analista, visto que este deve despender grandes esforços de representação psíquica daquilo que o paciente não consegue representar. As dificuldades encontradas, para realizar a análise de pacientes considerados difíceis, referem-se, segundo Kernberg et al. (1991), às fortes reações emocionais vinculadas à intensa transferência, experimentada desde o início da terapia, e à capacidade do terapeuta em suportar a ansiedade e a tensão psicológica provocada pelo paciente regredido.

Ao descrever os fenômenos clínicos de pacientes borderlines, Rey (1991) afirma que estes apresentam fenômenos tipicamente esquizoides, uma vez que regridem dramaticamente no setting analítico, manifestando intensa habilidade emocional. O processo analítico caracteriza-se como conturbado, sendo intercalado por períodos de intensa dependência associados a rupturas abruptas do processo de tratamento. Estes aspectos podem suscitar no analista diversos sentimentos intensos, tais como: ineficiência, incapacidade e irritação.

Para Figueiredo (2003), os casos difíceis colocam à prova as reservas do analista, podendo levá-lo à exaustão, visto que estes pacientes exigem atenção permanente, prontidão nas devolutivas e sustentação verbal e física. O autor discute, ainda, que a maior dificuldade na clínica dos casos difíceis é a capacidade do terapeuta em lidar com a intempestiva alternância dos afetos e dos estados, tornando-se imprescindível ao analista a compreensão da função a ser realizada e do lugar a ser ocupado.

A clínica dos casos considerados difíceis é, portanto, reconhecidamente desafiadora, na medida em que os pacientes têm uma atitude ambivalente, em relação aos cuidados terapêuticos oferecidos. Trata-se, portanto, de uma clínica limítrofe, que opera nas bordas da prática clínica, revelando situações analíticas, também, consideradas limítrofes, que remetem à própria questão nuclear da fragilidade das fronteiras psíquicas destes pacientes (CARDOSO, 2007; NAFFAH NETO, 2008).

\section{Contribuições Winnicottianas à Clínica dos Pacientes Difíceis}

A partir do trabalho com crianças em tenra idade e pessoas com distúrbios psíquicos graves, Winnicott (1983) desenvolveu um pensamento teórico-clínico original, dentro do campo da psicopatologia, ao propor a origem e a dinamização desses quadros nosológicos. Para o autor, a análise de pacientes borderlines possibilita a observação de fenômenos que direcionam à compreensão dos estados genuinamente esquizóides, visto que, embora esses indivíduos possuam a essência psicótica do distúrbio, também, apresentam uma organização psiconeurótica. Nesse sentido, os indivíduos considerados borderlines exteriorizam um quadro neurótico ou psicossomático, contudo, o distúrbio psicótico subjacente pode irromper em certas situações (WINNICOTT, 1975).

A origem destes transtornos cujo cerne é psicótico pode decorrer, de acordo com Winnicott (1983a), das recorrentes e intensas falhas do ambiente, ocorridas numa fase inicial do desenvolvimento do conjunto ambiente-indivíduo. O bebê que se encontra no início do seu processo de desenvolvimento emocional não possui ainda recursos psíquicos suficientes para lidar com a interferência de um ambiente privador. Para se proteger destas falhas, que são sentidas pelo bebê como ameaças à sua existência, este poderá mobilizar defesas, interrompendo o processo de desenvolvimento e, consequentemente, de sua constituição psíquica.

Compreende-se, de acordo com o pensamento winnicottiano, que a base constitutiva da saúde 
mental encontra-se nos estágios iniciais de constituição pessoal e engloba, necessariamente, os processos de desenvolvimento individual e as condições ambientais necessárias para que esta se realize. Desta forma, para haver uma investigação profunda da saúde mental do indivíduo, no sentido de ausência da psicose ou predisposição a esta, torna-se imprescindível uma investigação cautelosa dos processos primários e constitutivos do sujeito.

Para Winnicott (1983b), a análise dos pacientes difíceis ultrapassa as barreiras técnicas e a conduta profissional, já que lida com os aspectos mais primitivos do desenvolvimento emocional. Nesse sentido, a interpretação e o manejo voltados a estes pacientes devem ser possibilitados, por meio de um setting constante e sustentador, capaz de suprir as falhas ambientais iniciais, visando fornecer a provisão necessária à retomada do processo de desenvolvimento emocional (WINNICOTT, 1984). Reconhece-se que Winnicott propôs mudanças inovadoras na compreensão e na técnica da psicanálise voltada aos pacientes difíceis, tendo por base uma proposta que flexibiliza o enquadre clínico e amplia a concepção e o uso de interpretações, valorizando, assim, os atos do analista no manejo do enquadre (COELHO JUNIOR; JUNQUEIRA, 2008).

Alinhada às contribuições winnicottianas, Ungier (2008) ressalta que os pacientes considerados borderlines ou psicóticos convivem com a impossibilidade de ser, de modo que a possibilidade de retomada desta continuidade está relacionada ao acolhimento do gesto espontâneo do paciente no setting analítico. De acordo com Ferraz (2000, p. 106), "há sempre algo a ser feito, como nos ensinaram os analistas que ousaram tratar dos pacientes ditos 'difíceis' ou inacessíveis à análise. E este posicionamento não decorre de um mero princípio da técnica, mas, antes, de uma disposição ética".

Com base no reconhecimento da emergência desses quadros psicopatológicos na atualidade e das dificuldades encontradas no atendimento destes na clínica psicológica, este estudo teve como objetivo investigar, psicanaliticamente, o imaginário coletivo de psicólogos em formação a respeito do atendimento a pacientes considerados difíceis no setting analítico.

\section{Método}

A pesquisa pautou-se no referencial psicanalítico como método de investigação. A psicanálise revelase como um instrumento científico valioso, disposto a compreender o campo experiencial humano. Enfatiza-se que a psicanálise, ao ser adotada com método, deve, necessariamente, se orientar em elaborações interpretativas sustentadas sobre as técnicas de associação livre e atenção flutuante (MEZAN, 2002). Deste modo, à luz do método psicanalítico, este estudo buscou apreender os conteúdos imaginativos dos estudantes de psicologia atribuídos ao atendimento de pacientes considerados difíceis.

\section{Participantes}

Participaram, deste estudo, oito estudantes que frequentavam o oitavo semestre de um curso de graduação em Psicologia do interior paulista. Como critério de inclusão, estabeleceu-se que estes estudantes estivessem inseridos em um núcleo de estágio curricular supervisionado na área clínica, com o intuito de obter as associações dos psicólogos, no início de sua formação, ao realizar o exercício da prática clínica. Deste modo, privilegiou-se, nesse estudo, a formação inicial de psicólogos, na medida em que reconhece-se esse momento como imprescindível para o processo de estruturação formativa dos futuros psicólogos. 


\section{Instrumentos}

Utilizou-se o Procedimento de DesenhosEstórias com Tema, como recurso mediador, para a realização da entrevista grupal, com o intuito de captar o imaginário coletivo dos estudantes de Psicologia.

A partir do Procedimento de DesenhosEstórias (D-E) desenvolvido por Trinca (1997), Aiello-Vaisberg (1995) criou o Procedimento de Desenhos-Estórias com Tema (PDE-T), sendo este, igualmente, fundamentado nas teorias e práticas da psicanálise, nas técnicas projetivas e na entrevista clínica. Apresenta, em relação ao D-E, o diferencial de propor um tema específico, que possibilita o direcionamento da investigação. A utilização do PDE-T consiste na solicitação de um desenho específico em termos temáticos e, em seguida, o convite à invenção e narração de uma história sobre o desenho, finalizando com sua intitulação. A aplicação pode ser individual ou coletiva e abarcar sujeitos de qualquer faixa etária, em diferentes condições psicopatológicas, inclusive quadros graves, com variados graus de instrução formal e nível intelectual, o que confere grande versatilidade ao procedimento (AIELLO-VAISBERG, 1995).

Paradigmaticamente inspirado no Jogo do Rabisco e nas consultas terapêuticas de Winnicott (1994; 1984), o Procedimento de DesenhosEstórias com Tema, enquanto instrumento clínico, psicanaliticamente fundamentado e repensado à luz da transicionalidade, apresenta-se como uma possibilidade mediadora e dialógica, tendo em vista favorecer a facilitação expressiva da subjetividade grupal, o acesso a conteúdos inconscientes, além de possíveis transformações elaborativas inconscientes relativas ao imaginário coletivo (AIELLOVAISBERG, 1997).

Tachibana (2011) descreve que o pesquisador, ao lançar mão desse recurso para a realização desse tipo de investigação, deve criar condições para o estabelecimento de um ambiente suficientemente bom, a fim de aproximar os participantes, de forma relativamente tranquila, a temas que despertam conteúdos emocionais. Trata-se, assim, da apresentação gradual de temas mobilizadores em um ambiente adequado e protegido. Com base nessas orientações, a pesquisadora ofereceu um enquadre satisfatoriamente adequado e potencializador, na medida em que possibilitou o relaxamento das defesas, a expressão do gesto criativo das participantes e o estabelecimento da comunicação significativa.

\section{Procedimento de coleta e análise dos dados}

Todos os cuidados éticos referentes à conduta ética, na pesquisa com seres humanos, foram assegurados, de acordo com a Resolução no 196/96 do Conselho Nacional de Saúde. O projeto de pesquisa foi aprovado pelo Comitê de Ética em Pesquisa da Faculdade de Ciências e LetrasUNESP/Assis, sob o Processo $n^{\circ}$ 466/2009.

Realizou-se a entrevista grupal com os participantes, em que uma das pesquisadoras utilizou o PDE-T, em enquadre clínico diferenciado. Os participantes foram convidados a fazer uso individual, em ambiente coletivo, do PDE-T de acordo com a seguinte instrução: "Desenhe o atendimento psicoterápico de um paciente difícil", com base no esclarecimento de que estes se referem a pacientes diagnosticados como psicóticos, esquizóides e borderlines. Logo após a confecção do desenho, foi solicitado que escrevessem uma estória associada à produção gráfica e que a intitulassem. Em seguida, foi aberto um espaço, no qual os participantes pudessem se sentir à vontade para discutir sobre a temática abordada, expor sua produção e as experiências, discorrendo, livremente, sobre os sentimentos e os pensamentos suscitados.

Posteriormente, a pesquisadora que aplicou o PDE-T confeccionou uma narrativa psicanalítica, em que foi registrado o acontecer clínico, abarcando a articulação dos diálogos, as impressões despertadas e os sentimentos em relação ao encontro vivenciado 
(AIELLO-VAISBERG; MACHADO; AMBROSIO, 2004). Compreende-se que a narrativa é um procedimento coerente com o método psicanalítico, na medida em que esta apresenta o acontecer clínico do encontro inter-humano, por meio da reflexão, da vivência e do sentir do pesquisador (AIELLOVAISBERG; GRANATO, 2004). Com o intuito de promover maiores reflexões e propiciar a emersão de novas compreensões, a partir da multiplicidade de olhares, o material constituído pelos desenhosestórias e a narrativa foi compartilhado com a pesquisadora orientadora. Nesse momento, o material foi submetido à análise, de acordo com a Teoria dos Campos de Herrmann (1979), em busca da apreensão dos campos psicológicos não conscientes, segundo os quais se organiza o imaginário coletivo.

De acordo com Herrmann (1979, p. 107), “o campo é o inconsciente em sua ação concreta" e consiste em uma organização vital para o terreno da consciência, no qual sustenta, de modo significativo, as relações humanas que nele ocorrem, sendo indicativo do sentido das representações, palavras e sentimentos. Em interlocução com o pensamento de Bleger (1989), entende-se que toda relação, representação e conduta humana comporta um campo, de modo que as representações imaginativas podem ser compreendidas como um fenômeno transicional que envolve e permeia as condutas humanas (AIELLO-VAISBERG; MACHADO, 2005).

Segundo as indicações metodológicas propostas por Herrmann: "deixar que surja", "tomar em consideração" e "completar o desenho", ambas as psicólogas-pesquisadoras entraram em contato com os desenhos-estórias e a narrativa psicanalítica sustentadas em uma postura de atenção flutuante. Assim, as pesquisadoras se permitiram que fossem atravessadas e impressionadas pelo conteúdo emocional presente no material, o que possibilitou a atribuição de sentidos interpretativos e a criação de campos de sentidos.
Ressalta-se que o método psicanalítico não se limita em buscar um único significado em uma produção. Mas, consiste em revelar a multiplicidade de sentidos, intrínseco a todo discurso e conduta humana (AIELLO-VAISBERG, 1999). Logo, admite-se que a busca pelos campos de sentido afetivo-emocional contempla uma ampla gama de possibilidades interpretativas. Nesse sentido, a partir das múltiplas associações desveladas no encontro com os desenhos-estórias, pautamos a interpretação deste material por meio da captação dos campos de sentidos a partir dos quais ele emerge.

\section{Resultados e Discussões}

Com base na compreensão que os determinantes lógico-emocionais regem as condutas humanas, foram, interpretativamente, encontrados/criados campos de sentido afetivo-emocional, dentre os quais se apresentam os seguintes campos e subcampos: "Insegurança", "Terapeuta Perfeito", "Mutualidade", "Vivência", "Negação da Loucura" e "A Loucura como Tal".

\section{Campo Insegurança}

Revela-se, como predominante, o campo "Insegurança", que abarca concepções subjetivas referentes à insegurança, no exercício da prática clínica, dos estudantes de psicologia com os pacientes considerados difíceis. Infere-se que as representações suscitadas neste campo relacionam-se à inexperiência clínica, sendo esta uma característica peculiar desse momento inicial de formação, às expectativas em relação a esses pacientes, às fantasias e angústias suscitadas nesses atendimentos e, ainda, às exigências internas mobilizadas. 
Evidenciam-se, como exemplificado na Figura $1^{3}$, as dificuldades e a insegurança no manejo clínico realizado com estes pacientes. Sob este aspecto, Ribeiro (2008) afirma que a insegurança vivenciada pelos estudantes de Psicologia, no exercício da prática clínica, não se remete, exclusivamente, à estrutura emocional pessoal. Todavia, corresponde, também, ao escopo que envolve as relações significativas entre a teoria e a prática. Por sua vez, Saad (2011) compreende que, a despeito dos aparatos teóricos e clínicos, o terapeuta no setting analítico encontra-se meramente solitário e, somente, por meio da aquisição de reflexões sobre suas próprias experiências, associada à supervisão, é que terá condições de exercer seu ofício de forma autêntica.

Figura 1 - Desenho-Estória que compõe o campo Insegurança

Outro aspecto relevante, que compõe este campo psicológico-vivencial, consiste na configuração da relação analítica com estes pacientes permeada por sentimentos de insegurança, angústia e ansiedade. Nota-se, nos seguintes fragmentos, que este imaginário condiz com os sentimentos constratransferenciais despertados no psicoterapeuta que atua na clínica com os pacientes difíceis.

\footnotetext{
${ }^{3}$ A inclusão dos desenhos e das estórias no "corpus" do trabalho foi autorizada pelos participantes, conforme a declaração manifesta no Termo de Consentimento Livre e Esclarecido. Com o intuito de preservar eticamente o anonimato dos participantes e qualquer aspecto que possa identificá-los, alterou-se os nomes. Observa-se que as estórias foram transcritas conforme a redação apresentada pelos participantes, sendo assim preservadas conforme a versão original.
} 
As sessões são muito difíceis, pois Carlos grita o tempo todo, não quer brincar e tapa os ouvidos para não escutar nada. Ele ameaça ir embora toda hora, mas nunca vai. A terapeuta está "perdida", não sabe mais o que fazer (MARIA AMOR)

[...] Ele joga as peças em sua direção, dizendo várias palavras agressivas. A psicóloga fica amendrotada e sem saber o que fazer, tentando contê-lo e acolhê-lo. [...] (MARIA VIDA)

Com base nestas manifestações subjetivas, pode-se estabelecer uma interlocução com as contribuições de Aiello-Vaisberg e Machado (2005). As autoras afirmam que as dificuldades e as angústias, presentes no contato com os pacientes psicóticos, decorrem da vivência aterrorizante de aprisionamento do paciente que, por sua vez, remete o terapeuta às suas próprias angústias primitivas adormecidas. Para Safra (2004), os pacientes difíceis referem-se àqueles que sofreram uma intensa violência psíquica, em um período muito precoce da vida, levando-os a se constituírem em um estado de atordoamento primário. O autor, ainda, afirma que as dificuldades inerentes ao atendimento desses casos decorrem das situações tantalizadoras ao qual o analista é submetido, a fim de que o profissional possa, de forma semelhante, vivenciar e reconhecer a experiência aterrorizante que assolam os pacientes.

Inserido neste grande campo, encontramse outros subcampos, denominados: "Terapeuta Perfeito", "Mutualidade" e "Vivência".

\section{Subcampo Terapeuta Perfeito}

Retratam-se, neste subcampo, manifestações imaginárias referentes a um paciente idealizado. Admitem-se, por pacientes difíceis, aqueles de difícil análise, na medida em que despertam fortes reações emocionais contratransferenciais. Entretanto, as concepções subjetivas dos graduandos de Psicologia consistem na apreensão da loucura apenas como manifestações de agressividade, velando suas outras formas de expressão, como manifestado na Figura 2. Segundo Aiello-Vaisberg (1999), o louco revela, a partir de sua própria condição, a perda de sustentação e inter-relação entre sua identidade e a realidade. A experiência de loucura consiste na ruptura com o significado e a coexistência, além da manifestação de intensidades máximas de sofrimento psíquico.

Figura 2 - Desenho-Estória que constitui o subcampo Terapeuta Perfeito

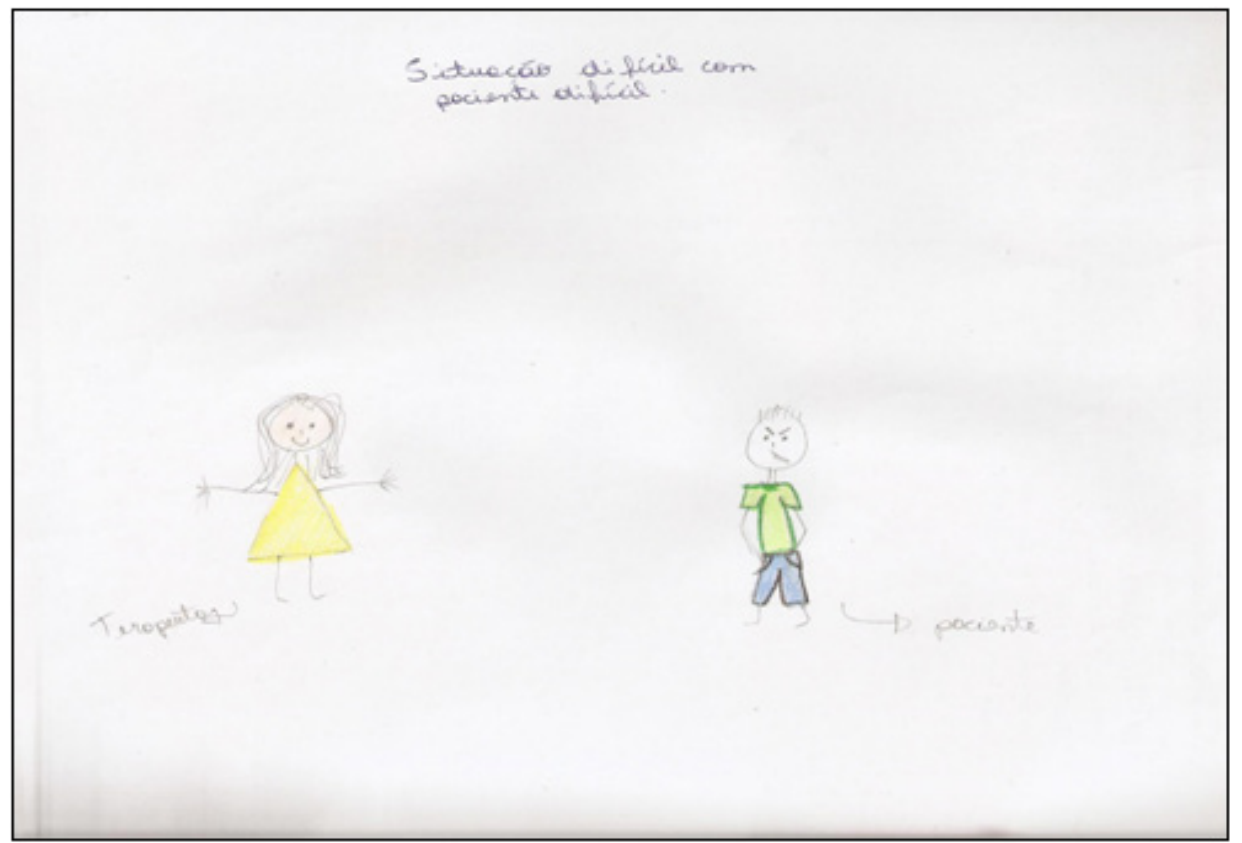


Outeiral (2001, p. 28) expõe a inevitabilidade de sentimentos negativos contratransferenciais surgidos com os pacientes difíceis, com base no pressuposto de que, "se determinado paciente sente o vazio, o caos e a destruição, ele não poderá fazer outra coisa senão tentar fazer sofrer e destruir o analista". Por outro lado, Aiello-Vaisberg e Mencarelli (2007) advertem que os sentimentos contratansferenciais despertados no setting analítico não podem ser mantidos latentes ou ignorados pelo terapeuta, já que a capacidade de reconhecimento destes afetos possibilita a presença viva e real do terapeuta no espaço analítico.

Winnicott (2000) considera imprescindível a necessidade da capacidade de identificação do terapeuta com seu paciente, sem que o profissional perca a sua própria identidade pessoal. Para o psicanalista, a possibilidade de continuidade do amadurecimento do terapeuta, rumo à sua independência profissional, encontra-se associada à sua capacidade de contato e expressão emocional. Desta forma, compreende-se que, para ocorrer um encontro clínico significativo, é necessário o estabelecimento de um senso de confiabilidade no vínculo terapêutico, o qual é oportunizado por meio da presença sensível do terapeuta, que possua condições de reconhecer sua própria ambivalência e os sentimentos contratransferenciais (KUPERMANN, 2008).

Ainda, segundo Winnicott, a mãe suficientemente boa é aquela que possui a capacidade de realizar uma adaptação sensível às necessidades de seu bebê, reconhecendo-o como ser humano e apresentandothe o mundo em pequenas doses. Desta forma, entende-se que assim como uma mãe suficientemente boa que oferta ao seu bebê os cuidados essenciais, o terapeuta, também, deve oferecer ao paciente as condições necessárias para que a continuidade de sua existência possa ser retomada. Esclarece-se, entretanto, que a mãe suficientemente boa, assim como o "terapeuta suficientemente bom", não são perfeitos, pois, enquanto seres humanos, também, falham, de forma gradual e sensível, tendo em vista facilitar o processo inato de desenvolvimento.
Nesse sentido, este campo psicológico-vivencial constitui-se, predominantemente, na crença segundo o qual o terapeuta precisa ser perfeito, ou seja, que possua condições de oferecer ao paciente todo o suporte necessário. Entretanto, com o intuito de concretizar essa sustentação, relegam, a um plano secundário, os reais sentimentos mobilizados. Nesse sentido, entende-se que o imaginário, em relação a esse terapeuta, apresenta-se idealizado, pois os estudantes não reconhecem, de forma íntegra e consciente, a presença de sentimentos contratransferenciais perante o paciente que tanto lhe ataca.

Infere-se, deste modo, a presença de um imaginário idealizado frente ao paciente, pois, apesar dos estudantes reconhecerem as dificuldades em analisá-los, não revelam o real sofrimento despertado, ao entrarem em contato com a loucura do paciente. Abstiveram-se, assim, de expor os sentimentos negativos contratransferenciais que, inevitavelmente, surgem nesse tipo de atendimento, apresentando somente ansiedades e angústias circunscritas ao âmbito da prática clínica.

\section{Subcampo Mutualidade}

Em contrapartida, o subcampo da Mutualidade organiza-se a partir do reconhecimento dos sentimentos contratransferenciais mobilizados no atendimento de pacientes difíceis, além da manifestação de atuações clínicas espontâneas e genuínas. Nota-se, na estória de Maria Flor, que, ao entrar em contato com o sofrimento do paciente e reconhecer as suas próprias angústias, o terapeuta, ainda que mobilizado, apresenta-se real e presente.

\footnotetext{
No início de um processo psicoterápico, o paciente "apronta" todas as situações que causam muita ansiedade na terapeuta, que fica paralisada sem saber como agir, que atitudes tomar. Percebe-se que o paciente está "testando" o ambiente, descobrindo-o. Porém as reações do paciente deixa a terapeuta perdida, pensando "como agir com esse paciente?", "onde posso buscar essas respostas?” E o processo se segue, sendo que o paciente e o terapeuta vão
} 
se conhecendo... construindo um vínculo seguro. Podendo assim, essas ansiedades mútuas serem amenizadas (MARIA FLOR).

Segundo Winnicott (1984), a possibilidade de sentir-se real é mais do que existir, é uma forma de descobrir um modo de existir como si mesmo, em relacionar-se com os objetos e ter um eu para qual se retirar para o relaxamento. Entende-se que o acontecer clínico relaxado e espontâneo, decorrente de uma conduta íntima e sensível por parte do terapeuta, possibilita um encontro mais humano, na medida em que este sem facetas e defesas se permite ser afetado e acolher o que lhe afeta.

Observa-se que a insegurança permeia as concepções subjetivas deste subcampo. Entretanto, o terapeuta não se manifesta de forma idealizada, apresentando-se como possuidor de fraquezas, falhas e angústias. Nesse sentido, Saad (2011, p. 46) destaca que a rigidez técnica e a assepsia do setting não resultará em análises satisfatoriamente bem sucedidas, pois a relevância do trabalho analítico consiste em todo "o conjunto de procedimentos e ações, de interações e comunicações e, sobretudo, a pessoa real do analista e do analisando ali, genuinamente, no encontro de cada sessão, estando ambos postados na sua verdade pessoal e particular". Com base nestas considerações, admite-se que o reconhecimento do próprio sofrimento, ante a loucura desconcertante do paciente, possibilita um contato terapêutico mais sensível e autêntico.

\section{Subcampo Vivência}

Neste último subcampo, apresentam-se manifestações imaginárias referentes à experiência do atendimento de um paciente difícil. As representações revelam a insegurança do terapeuta frente a esse paciente, assim como a mobilização de angústias e a vivência deste encontro. A vivência da situação analítica pelo aluno não se encontra mais no plano idealizado e do imaginário. Porém, apresentase mais real, devido à sua experiência clínica.
Segundo o pensamento winnicottiano, a psicoterapia configura-se por meio do brincar de duas pessoas. Nesse sentido, o brincar é concebido como princípio norteador para a prática clínica psicanalítica, sendo oportunizado por meio do encontro com o si-mesmo, da comunicação e da intersecção entre a realidade e o mundo do paciente e do terapeuta. Manifesta-se, sustentado no brincar, a possibilidade de vivência do encontro interhumano e, uma vez vivenciado, as representações se desnudam de forma espontânea e amadurecida. Sob este aspecto presente neste subcampo de sentido, Boraks (2008) afirma que o processo de amadurecimento, promovido pela vitalidade presente nas relações inter-humanas, possibilita a transformação de um acontecimento em experiência.

De acordo com Aiello-Vaisberg (2003, p. 123), "sustentar o encontro inter-humano é algo que tem sentido, quando se tem fé na capacidade criadora humana". Compreende-se que a experiência analítica pautada em dimensões éticas exige do analista certo grau de amadurecimento emocional, visto que, somente a partir dessa maturidade, tornase possível reconhecer o outro em sua historicidade, vulnerabilidade e alteridade (AIELLO-VAISBERG; MEDEIROS, 2005). No fragmento de Maria Luz, "o vínculo e a confiança depois dessa postura de estar ali com ela, do jeito que ela poderia estar nesse encontro, foi se estabelecendo e o contato rolando... no sentido de caminhar para o acolhimento, de estar com ela como ela pode estar e se relacionar no momento", presentificam-se a experiência de vivência clínica e a manifestação de um imaginário próximo da realidade clínica, não sendo idealizado.

Deste modo, observam-se, neste subcampo, manifestações subjetivas amadurecidas, pois, uma vez experienciado o encontro terapêutico e tendo-o elaborado, torna-se possível apresentar uma conduta clínica mais presentificada e real. Diferencia-se o imaginário idealizado do terapeuta que ainda não teve essa experiência clínica, tal como evidenciado no subcampo "Terapeuta Perfeito", do imaginário do terapeuta que já fez esta passagem, como exposto neste subcampo. 


\section{Campo Negação da Loucura}

Este campo de sentido afetivo-emocional referese à impossibilidade do terapeuta em entrar em contato com a loucura do paciente, em razão da intensa angústia mobilizada no setting analítico com esses casos clínicos. Nota-se, no fragmento de Maria Bela, que a representação imaginativa deste tipo de atendimento que possui caracterizadamente elementos regressivos, nem sequer conseguiu ser realizada.

[...] Ele pulou compulsivamente sobre o sofá e posteriormente subiu na mesa. Em cima da mesa ele disse que queria voar, levantando o braço o mais alto possivel. A psicóloga perguntou então para onde ele gostaria de voar, e pulando de volta para o sofá gritou "pra bem longe" (MARIA BELA).

As dificuldades do terapeuta em conseguir entrar em contato com a loucura do paciente concorrem para a edificação de defesas, levando o profissional a tornar as angústias suscitadas no setting analítico em algo minimamente suportável para ele. Em relação a estes aspectos, admite-se a dificuldade inerente a estes atendimentos, na medida em que "os pacientes insanos representam uma pesada carga emocional para os que deles cuidam" (WINNICOTT, 2000, p. 277). A analisabilidade dos casos difíceis convoca o terapeuta a alcançar, em sua própria análise, os níveis mais primitivos. Conjetura-se, assim, que o analista, que se propõe a analisá-los, deve estar consciente dos sentimentos negativos que lhe serão atribuídos. Pressupõe-se que terapeutas devam estar cientes das dificuldades que pacientes difíceis evocam e, ainda, devam buscar, em sua análise pessoal ou supervisão de casos clínicos, o suporte necessário para ser um terapeuta suficientemente bom, nestes casos.

Por sua vez, Abram (2008) afirma que o terror se faz presente em diversas análises, porém, atualiza-se imperiosamente no setting analítico com os pacientes difíceis, visto que o senso de terror configura-se, essencialmente, como psicótico. Com base nessas proposições, admite-se, nesse campo de sentido, que a iminência da sensação de terror, pelo terapeuta nestes atendimentos, o conduz a representar a loucura do paciente por meio de artifícios defensivos, apresentando-o de forma encoberta sob uma faceta suportável.

\section{Campo A Loucura como tal}

De outro modo, esse campo do imaginário congrega produções que se articulam ao redor da regra lógico-emocional de que o sofrimento apresentado pelo paciente difícil é tão intenso, que se torna excessivamente insustentável ao profissional. Nota-se, na Figura 3, que o terapeuta, ao presenciar a loucura de seu paciente, não consegue estar ali com ele e para ele, mantendo-se oculto diante de tanto sofrimento. Evidencia-se, nesse campo psicológico, a manifestação fatídica de angústias intensas e, ainda, a possibilidade de falhas, por parte do terapeuta, no atendimento deste paciente. Esta representação imaginativa alcança a manifestação do enlouquecimento, além de expor as falhas do terapeuta e os sentimentos contratransferenciais despertados, tais como: incapacidade, impotência e o temor do próprio enlouquecimento. 
Figura 3 - Desenho-Estória que constitui o campo A Loucura Como Tal

Entende-se que vivenciar a loucura, tal como ela se apresenta, exige do terapeuta certo grau de amadurecimento emocional, além de disponibilidade interna e integridade psíquica, ou seja, condições consideradas essenciais para lidar com demasiado sofrimento humano. Para Figueiredo (2003), o contato íntimo e real com o sofrimento que entorna do paciente mobiliza angústias primitivas, assim como áreas obscuras e caóticas da mente e do corpo do analista. Nesse sentido, reconhece-se que este campo de sentido encontra-se alinhado ao pressuposto de que a clínica com os pacientes difíceis se revela como uma clínica limítrofe.

Com alguns borderlines, a manutenção do holding é muito sofrida, devido aos períodos repetidos em que o paciente fica desafiando os parâmetros analíticos, fazendo demandas inapropriadas, ataques verbais violentos e dizimadores ou sarcasmos e ironias, todos despertando ódio e reações negativas no analista que fica, às vezes, desejoso de interromper o holding e a própria análise. Algumas vezes a própria contenção do analista pode ser sentida como descaso. Na realidade, o paciente necessita de duas coisas: ferir o analista e atingi-lo (deve perceber que pode causar sofrimento), e, ao mesmo tempo, que o analista não interrompa a análise (FORLENZA NETO, 2004, p. 312).

Em consonância com Aiello-Vaisberg e Medeiros (2005), admite-se que a condição essencial para o estabelecimento do acontecer clínico contempla a necessidade da presença viva, real, responsável e passiva de afetação por parte do analista. Por outro lado, Maia (2009) propõe que a experiência-deexistir-com-o-outro apresenta-se como condição imprescindível para a ética do cuidado que permeia as relações inter-humanas. Este campo de sentido afetivo-emocional possibilita, portanto, a compreensão de que a dimensão relacional do encontro analítico demanda a presença da pessoa 
real do terapeuta, sustentada na ética do cuidado voltada à possibilidade destes pacientes de se sentirem reais.

\section{Conclusões}

O estudo realizado por meio da aplicação do Procedimento de Desenhos-Estórias com Tema em enquadre transicional de entrevista grupal, sustentado no método psicanalítico, permitiu articulação de reflexões teórico-clínicas sobre a clínica psicológica da atualidade dos casos considerados difíceis. Os dados encontrados permitiram apreender o imaginário coletivo de graduandos de psicologia sobre o atendimento clínico destes pacientes. Foram captados campos e subcampos de sentido afetivo-emocional denominados "Insegurança", "Terapeuta Perfeito", "Mutualidade", "Vivência", "Negação da Loucura" e "A Loucura como Tal", que possibilitaram identificar a percepção de um imaginário coletivo, no qual o atendimento psicológico destes casos clínicos é concebido, principalmente, por sensações de insegurança, angústia, ansiedade, incapacidade e impotência.

Os resultados alinham-se às discussões presentes na literatura discutida, de que a clínica com os pacientes difíceis revela-se, particularmente, como uma clínica limítrofe, em que são mobilizados intensos sentimentos contratransferenciais. Os dados encontrados revelam, portanto, as características e as particularidades inerentes à clínica contemporânea dos casos considerados difíceis. Admitem, ainda, reflexões e questionamentos sobre a influência da formação acadêmica, com suas possíveis repercussões na prática clínica dos futuros profissionais de psicologia.

Observamos de forma predominante a manifestação de insegurança no atendimento clínico destes pacientes, decorrente das dificuldades encontradas em exercer o manejo clínico, nesse momento particular de formação profissional, o que é esperado e deve ser trabalhado pelos professores supervisores do curso. O formando em Psicologia, ao se deparar com a prática clínica, manifesta expectativas e fantasias em relação ao seu papel, às suas condutas exercidas no setting analítico e ao paciente. Infere-se que, no decorrer das experiências profissionais, associadas ao amadurecimento emocional do aluno, as expectativas vão se tornando menos idealizadas, contribuindo, assim, para a possibilidade da internalização do papel profissional de psicólogo.

Em termos do imaginário coletivo da atualidade, este estudo clínico-interventivo confluiu para a elaboração de reflexões no âmbito das dificuldades e impasses encontrados na clínica com estes pacientes e, ainda, possibilitou, ao aluno de psicologia, depararse com suas concepções, imagens e fantasias sobre o atendimento desses pacientes, contribuindo para que os futuros profissionais exerçam, na prática clínica, atuações, potencialmente, transformadoras, por meio de um reposicionamento existencial mais íntegro e autêntico.

\section{Referências}

ABRAM, J. O objeto não sobrevivente: algumas reflexões sobre as raízes do terror. Revista Brasileira de Psicanálise, São Paulo, v. 42, n. 1, p. 153-171, 2008.

AIELLO-VAISBERG, T. M. J. Encontro com a loucura: transicionalidadee ensino depsicopatologia. 1999. 185f. Tese (De Livre Docência) - Universidade de São Paulo, São Paulo. 1999.

Investigação de representações sociais. In: TRINCA, W. (Org.). Formas de investigação clínica em psicologia: procedimento de desenhos-estórias: procedimento de desenhos de famílias com histórias. São Paulo: Vetor, 1997. p. 255-288.

O uso de procedimentos projetivos na pesquisa de representações sociais: projeção e tansicionalidade. Psicologia USP, São Paulo, v. 6, n. 2, p. 103-127, 1995. 
. Psicopatologia e contemporaneidade. In: ENCONTRO DE PSICOLOGIA DA SAÚDE, 2., 2007, São Paulo. Anais... São Paulo: Universidade Presbiteriana Mackenzie, São Paulo, 2007. p. 1-13.

. Ser e fazer: interpretação e intervenção na clínica Winnicottiana. Psicologia USP, São Paulo, v. 14, n. 1, p. 95-128, 2003.

AIELLO-VAISBERG, T. M. J.; GRANATO, T. M. M. Tecendo a pesquisa clínica em narrativas psicanalíticas. Mudanças: Psicologia da Saúde, São Paulo, v. 12, n. 2, p. 253-271, 2004.

AIELLO-VAISBERG, T. M. J.; MACHADO, M. C. L. Narrativas: o gesto do sonhador brincante. In: ENCONTRO LATINO AMERICANO DOS ESTADOS GERAIS DA PSICANÁLISE, 4., 2005, São Paulo . Anais.... São Paulo, 2005. São Paulo: Instituto Sedes Sapientiae, 2005. p. 1-11.

AIELLO-VAISBERG, T. M. J.; MACHADO, M. C. L.; AMBROSIO, F. F. A alma, o olho e a mão: estratégias metodológicas de pesquisa na psicologia clínica social winnicottiana. In: AIELLOVAISBERG, T. M. J. Ser e fazer: enquadres diferenciados na clínica winnicottiana. São Paulo: Idéias e Letras, 2004. p. 6-16.

AIELLO-VAISBERG, T. M. J.; MEDEIROS, C. Fios da vida e da morte: tecendo reflexões entre o holding e a ética. In: AIELLO-VAISBERG, T. M. J.; AMBROSIO, F. F. (Org.). Cadernos Ser e Fazer: Reflexões Éticas na Clínica Contemporânea. São Paulo: Instituto de Psicologia da Universidade de São Paulo, 2005. p. 91-104.

AIELLO-VAISBERG, T. M. J.; MENCARELLI, V. L. Contratransferência e compaixão: encontro clínico com um rapaz HIV+. Psicologia clínica, Rio de Janeiro, v. 19, n. 1, p. 93-107, 2007.

BLEGER, J. A psicologia da conduta. 2. ed. Tradução de Emilia de Oliveira Diehl. Porto Alegre: Artes Médicas, 1989.

BORAKS, R. A capacidade de estar vivo. Revista Brasileira de Psicanálise, São Paulo, v. 42, n. 1, p. 112-123, 2008.
CARDOSO, M. R. A impossível "perda" do outro nos estados limites: explorando as noções de limite e alteridade. Psicologia em Revista, Belo Horizonte, v. 13, n. 2, p. 325-338, 2007.

COELHO JUNIOR, N.; JUNQUEIRA, C. Interpretação e manejo do enquadre na clínica de pacientes-limite. Tempo Psicanalítico, Rio de Janeiro, v. 40, n. 1, p. 137-157, 2008.

FERENCZI, S. Análise de crianças com adultos. In: Psicanálise. Tradução de Álvaro Cabral. São Paulo: Martins fontes, 1992. p. 69-83. (Obras completas, v. 4).

FERRAZ, F. C. Perversão. São Paulo: Casa do Psicólogo, 2000.

FIGUEIREDO, L. C. A clínica borderline. In: Psicanálise: elementos para a clínica contemporânea. São Paulo: Escuta, 2003, p. 109-126.

FIGUEIREDO, L. C. Subjetivação e esquizoidia na contemporaneidade: questões metapsicológicas. Cadernos de Psicanálise: CPRJ, Rio de Janeiro, v. 16, n. 19, p. 13-32, 2000.

FORLENZA NETO, O. Aplicação das ideias de Winnicottna clínica de pacientes difíceis (esquizoides, fronteiriços e psicóticos). Natureza Humana: Revista Internacional de Filosofia e Práticas Psicoterápicas, São Paulo, v. 6, n. 2, p. 307-335, 2004.

GREEN, A. Conferências brasileiras de André Green: metapsicologia dos limites. Rio de Janeiro: Imago, 1990.

HERRMANN, F. Andaimes do real: o método da psicanálise. São Paulo: EPU, 1979.

KERNBERG,O.T.; SELZER, M.A.; KOENISBERG, H. W.; CARR, A. C.; APPELBAUM, A. H. Psicoterapia psicodinâmica de pacientes borderline. Tradução de Rita de Cássia Sobreira Lopes. Porto Alegre: Artes Médicas, 1991.

KUPERMANN, D. Presença sensível: cuidado e criação na clínica psicanalítica. Rio de Janeiro: Civilização Brasileira, 2008. 
LUZ, A. B. Ferenczi: grão-vizir ou enfant terrible. Revista Brasileira de Psicanálise, São Paulo, v. 44, n. 2, p. 17-22, 2010.

MAIA, M. S. Crianças do porão: descuido, violência psíquica e cuidado. In: MAIA, M. S. (Org.). Por uma ética do cuidado. Rio de Janeiro: Garamond, 2009, p. 357-377.

MAIA, M. S. Extremos da alma: dor e trauma na atualidade e clínica psicanalítica. Rio de Janeiro: Garamond, 2003.

MEZAN, R. Interfaces da psicanálise. São Paulo: Companhia das letras, 2002.

NAFFAH NETO, A. O caso Margaret Little: Winnicott e as bordas da psicanálise. Jornal de Psicanálise, São Paulo, v. 75, n. 41, p. 107-121, 2008.

OUTEIRAL, J. Clínica da transicionalidade: fragmentos da análise de uma adolescente. Rio de Janeiro: Revinter, 2001.

PINTO, A. M. F. Sobre a dificuldade de exercer a função analítica em paciente borderline. Psicanalítica, Rio de Janeiro, v. 7, n. 1, p. 103-118, 2006.

REY, J. R. Fenômenos esquizoides no paciente fronteiriço. In: SPILLIUS, E. B. (Org.). Melanie Klein hoje. Tradução de Belinda Mandelbaum. Rio de Janeiro: Imago, 1991. v. 1.

RIBEIRO, D. P. S. A. Transicionalidade e uso do procedimento de desenho-estória com tema nas primeiras entrevistas clínicas. 2008. Tese (Doutorado em Psicologia) - Pontifícia Universidade Católica de Campinas, Campinas. 2008.

SAAD, A. A. C. Da delicada complexidade do encontro analítico. Revista Brasileira de Psicanálise, São Paulo, v. 45, n. 3, p. 41-50, 2011.

SAFRA, G. A po-ética na clínica contemporânea. Aparecida: Idéias \& Letras, 2004.

SILVA, J. F. R.; YAZIGI, L. Dois vértices da investigação de pacientes borderlines: a clínica psicanalítica e a avaliação psicológica. Revista Brasileira de Psicanálise, São Paulo, v. 38, n. 3, p. 621-636, 2004.
TACHIBANA, M. Fim do mundo: o imaginário da equipe de enfermagem sobre a gravidez interrompida. 2011. Tese (Doutorado em Psicologia) - Pontifícia Universidade Católica de Campinas, Campinas. 2011.

TRINCA, W. Formas de investigação clínica em psicologia: procedimentos de desenhos-estórias: procedimento de desenhos de família com estórias. São Paulo: Vetor, 1997.

UNGIER, A. Por uma psicanálise bem temperada. Revista Brasileira de Psicanálise, São Paulo, v. 42, n. 1, p. 43-51, 2008.

WINNICOTT, D. W. Classificação: existe uma contribuição psicanalítica à classificação psiquiátrica? In: . O ambiente e os processos de maturação: estudos sobre a teoria do desenvolvimento emocional. Tradução de Irineo Constantino Schuch Ortiz. Porto Alegre: Artmed, 1983. p. 114-127.

\section{Consultas terapêuticas em psiquiatria}

infantil. Tradução de Joseti Marques Xisto Cunha. Rio de Janeiro: Imago, 1984.

- Distorção do ego em termos de falso e verdadeiro "self". In: $O$ ambiente $e$ os processos de maturação: estudos sobre a teoria do desenvolvimento emocional. Tradução de Irineo Constantino Schuch Ortiz. Porto Alegre: Artmed, 1983a. p. 128-139.

. Contratransferência. In: . O ambiente

e os processos de maturação: estudos sobre a teoria do desenvolvimento emocional. Tradução de Irineo Constantino Schuch Ortiz. Porto Alegre: Artmed, 1983b. p. 145-151.

. O Jogo do rabisco. In: WINNICOTT, D. W.; SHEPPHERD, R.; DAVIS, M. (Org.). Explorações psicanalíticas: D. W. Winnicott. Tradução de José Octavio de Aguiar Abreu. Porto Alegre: Artes Médicas, 1994. p. 230-243.

. O ódio na contratransferência. In:

Da pediatria à psicanálise: obras escolhidas. Tradução de Davy Bogomoletz. Rio de Janeiro: Imago, 2000. p. 277-287. 
- O uso de um objeto e relacionamento através de identificações. In: . O brincar e a realidade. Tradução José Octavio de Aguiar Abreu e Vanede Nobre. Rio: Imago, 1975, p. 121-131.

Variedades de psicoterapia. In:

Privação e delinquência. Tradução de Álvaro Cabral. São Paulo: Martins fontes, 1984. p. 237-246.

ZAMBELLI, C. K.; TAFURI, M. I.; VIANA, T. D. C.; LAZZARINI, E. R. Sobre o conceito de contratransferência em Freud, Ferenczi e Heimann. Psicologia Clínica, Rio de Janeiro, v. 25, n. 1, p. 179-195, 2013. 